\title{
DESIGUALDADES NO ESTADO DO RIO GRANDE DO SUL: ANÁLISE DE INDICADORES SOCIAIS E EDUCACIONAIS ${ }^{1}$
}

\author{
Inequalities in the State of Rio Grande do Sul: analysis of social and \\ educational indicators
}

\section{Desigualdad en el Estado del Rio Grande do Sul: análisis de los indicadores sociales y educativas}

\author{
Evandro Ricardo Guindani*
}

Yáscara Michele Neves Koga**

Sandro Ben Hur Gonçalves do Nascimento ${ }^{* * *}$

\section{Resumo}

O presente artigo busca contribuir com investigações acerca da realidade socioeconômica e a sua influência no contexto educacional. A problemática deste estudo se fundamenta numa análise entre os indicadores educacionais e indicadores socioeconômicos e evidencia que há uma relação diretamente proporcional entre uma dimensão e outra. A referida análise dos dados busca comparar os municípios situados na fronteira e aqueles situados na região central e serrana do Estado do Rio Grande do Sul. A metodologia utilizada foi de coleta e análise de dados a partir de fontes oficiais tais como o Instituto Brasileiro de Geografia e Estatística - IBGE (2013) e o Instituto Nacional de pesquisas em Educação Anísio Teixeira - INEP (MEC, 2013). A análise foi realizada a partir dos conceitos de capital cultural, configurações familiares, educação e desenvolvimento econômico. Os resultados demonstram que há uma intrínseca relação entre indicadores sociais e educacionais bem como uma clara disparidade entre a fronteira e região central do Estado. O desafio que se coloca é a urgente necessidade de políticas públicas que venham promover uma igualitária distribuição de renda, bem como um justo e equitativo desenvolvimento socioeconômico entre as regiões do Estado.
\end{abstract}

PALAVRAS-CHAVE: Realidade socioeconômica. Indicadores educacionais. Desigualdade regional.

\begin{abstract}
This article aims to contribute with research on the socioeconomic reality and its influence in the educational context. The problem of this study is based on an analysis between educational indicators and socioeconomic indicators and shows that there is a directly proportional relationship between one dimension and another. This data analysis seeks to compare the municipalities located at the border and those located in the central and mountainous region of the State of Rio Grande do Sul. The methodology used was to collect and analyze data from official sources such as the Brazilian Institute of Geography And Statistics - IBGE (2013) and the National Institute of

${ }^{1}$ O conteúdo deste trabalho foi apresentado no III Seminário Internacional de Ciências Sociais - Ciência Política: Buscando o Sul. Universidade Federal do Pampa. São Borja-RS. 18 a 22 de agosto de 2014

Professor Adjunto da Universidade Federal do Pampa - Unipampa - Bagé-RS. evandroguindani@unipampa.edu.br

** Professora Adjunta da Universidade Federal do Pampa - Unipampa - Bagé-RS. yascara.koga@gmail.com

*** Mestrando em Políticas Públicas na Universidade Federal do Pampa - Unipampa - São Borja-RS. sandrix999@yahoo.com.br
\end{abstract}


Research in Education Anísio Teixeira - INEP (MEC, 2013). The analysis was made from the concepts of cultural capital, family settings, education and economic development. The results show that there is an intrinsic relationship between social and educational indicators as well as a clear disparity between the border and the central region of the State. The challenge is the urgent need for public policies that promote an equal distribution of income, as well as a fair and equitable socio-economic development between the regions of the State

KEYWORDS: Socioeconomic reality. Educational indicators. Regional inequality.

\section{Resumen}

En este artículo se pretende contribuir a la investigación sobre la realidad socio-económica y su influencia en el contexto educativo. El problema de este estudio se basa en un análisis de los indicadores y los indicadores educativos y socioeconómicos muestra que existe una relación directamente proporcional entre una dimensión y otra. El análisis de estos datos pretende comparar los municipios de la frontera y las localizadas en la región central y la sierra de Rio Grande do Sul. La metodología utilizada fue la recopilación y análisis de datos de fuentes oficiales como el Instituto Brasileño de Geografía y Estadísticas - IBGE (2013) y el Instituto de investigación Nacional de Educación Teixeira - INEP (MEC, 2013). Se llevó a cabo el análisis basado en los conceptos de capital cultural, la estructura familiar, la educación y el desarrollo económico. Los resultados muestran que existe una relación intrínseca entre los indicadores sociales y educativas y una clara disparidad entre la frontera y la región central del estado. El desafío que se plantea es la necesidad urgente de políticas públicas que promuevan una distribución equitativa de los ingresos, así como el desarrollo socioeconómico justa y equitativa entre las regiones del estado

PALABRAS CLAVE: La realidad socio-económica. Indicadores educativos. La desigualdad regional.

\section{INTRODUÇÃO}

O presente estudo tem como objetivo colaborar no debate sobre as implicações da realidade socioeconômica no contexto escolar dos alunos. A relação entre o nível socioeconômico familiar e os indicadores educacionais - expressos pelo İndice de Desenvolvimento da Educação Básica - IDEB - apontam que a disparidade entre o desenvolvimento socioeconômico pode ser determinante para o desempenho escolar dos alunos. A definição da amostra se deu a partir das Coordenadorias Regionais de Educação (CRE) que agregam municípios por região geográfica. Diante desse critério, optamos por trabalhar com três CREs, sendo elas: a $10^{\mathrm{a}}$, a $35^{\mathrm{a}}$ - que incluem os municípios da fronteira oeste do Estado do Rio Grande do Sul - e a $4^{\mathrm{a}}$ - que incluem os municípios mais próximos à capital do Estado e região serrana.

O objeto desta investigação assentou-se sobre uma reflexão em torno de duas dimensões vinculadas à educação, sendo eles, os indicadores educacionais e socioeconômicos dos municípios. Com relação aos indicadores educacionais optamos pelo Índice de Desenvolvimento da Educação Básica - IDEB, que produz um indicador resultante da relação entre a proficiência dos alunos em português e matemática com as taxas de aprovação e reprovação da escola. Com relação aos indicadores socioeconômicos optamos pelo Índice de Desenvolvimento Humano - IDH; percentual de indigência e pobreza e desigualdade de renda. O recorte geográfico da análise buscou problematizar as especificidades da fronteira - com ênfase na cidade de São Borja - em relação à região central e serrana do Estado com melhores índices socioeconômicos. A delimitação 
temporal da análise foi de 2010 a 2011 pelo fato do IDH ser gerado a cada dez anos, paralelo a isso trabalhamos com o Ideb mais próximo de 2010 que seria de 2011.

Ao refletirmos acerca da relação entre a educação e a realidade socioeconômica, não podemos deixar de considerar a afirmação de Mészáros (2005, p.25) quando afirma que: "os processos educacionais e os processos sociais mais abrangentes de reprodução estão intimamente ligados". Por um lado qualquer projeto socioeconômico necessita, para ser executado, de uma mediação educacional e por outro, que a realidade socioeconômica determina o modelo e a qualidade da educação. Importa ressaltar, que esta mediação educacional, necessária a qualquer projeto socioeconômico faz com que haja um papel determinante de um determinado sistema econômico no que tange ao direcionamento das políticas educacionais.

É importante observarmos que diante da crise de um sistema econômico renova-se o discurso de dominação e da busca de bodes expiatórios para a crise. O primeiro elemento que fortemente passa a compor esse bode expiatório é o individuo e sua capacidade de superação da crise, que deve se dar por meio da busca por qualificação profissional. Cabe a ele e somente ao seu talento, criatividade e caráter inovador, a possibilidade de conquistar um espaço nesta sociedade do conhecimento e ao mesmo tempo da incerteza. Diante da crise de um sistema econômico, a educação passa a ser vista como a saída para a superação dos problemas individuais e sociais. E aí entram em cena os organismos internacionais que fazem esse papel de disseminar uma determinada ideologia educacional salvacionista. De acordo com Frigoto e Ciavata (2003) os anos de 1990 registram a presença dos organismos internacionais que entram em cena em termos organizacionais e pedagógicos, marcados por grandes eventos, assessorias técnicas e farta produção documental. O primeiro desses eventos é a Conferência Mundial sobre Educação para Todos, realizada em Jomtien, Tailândia, de 5 a 9 de março de 1990, que inaugurou um grande projeto de educação em nível mundial, para a década que se iniciava, financiada pelas agências UNESCO, UNICEF, PNUD e Banco Mundial. A Conferência de Jomtien apresentou uma visão para o decênio de 1990 e tinha como principal eixo a ideia da satisfação das necessidades básicas de aprendizagem.

As contribuições dos teóricos acima nos apontam que - dada a importância da educação para o funcionamento da economia capitalista - ela passa a assumir um papel central no discurso dominante, tanto de políticos quanto dos próprios meios de comunicação. Prolifera-se uma ideologia da educação como a grande responsável pela transformação social e consequentemente o principal ingrediente para a superação da pobreza. Ao mesmo tempo que se responsabiliza a educação, desenvolve-se uma lógica de culpabilização da escola e dos professores pelos baixos índices de desempenho e rendimento dos alunos. Como vimos acima, esta concepção está ancorada na própria lógica do sistema econômico que legitima a culpabilização individual pelo fracasso. Diante do exposto, buscaremos refletir neste artigo, como não se pode responsabilizar unicamente as escolas pela tarefa do sucesso escolar dos alunos e como se faz necessário um questionamento da lógica econômica em que vivemos, antes de fomentarmos um discurso salvacionista da educação. A seguir desenvolveremos uma reflexão que buscará demonstrar como as reflexões sobre qualidade da educação e rendimento dos alunos precisam serem pensadas a partir dos elementos que compõe o contexto dos alunos, tais como a família e a realidade socioeconômica, bem como seu espaço geográfico, no nosso caso específico, a fronteira. 


\title{
A necessária relação entre a realidade socioeconômica e o rendimento escolar do aluno
}

A infância e adolescência são etapas da vida - em que se encontra a grande maioria dos alunos - fortemente marcada pelo desenvolvimento físico, psíquico, emocional e social do ser humano, sendo de extrema importância a garantia da proteção social nestes ciclos. A proteção social em primeira instância é oferecida no espaço privado, na família, e em segunda no espaço público, no Estado. A desigualdade, exclusão social e pauperização acarretadas pelo modo de produção capitalista acabam por fragilizar a família cada vez mais no que tange a proteção social de seus membros e à garantia do acesso aos direitos sociais. A pauperização deixa a camada mais pobre da população em situação de vulnerabilidade social, a qual interfere diretamente no desempenho e na mobilidade social da população.

Sabe-se que a condição socioeconômica familiar bem como o acesso a bens culturais interfere diretamente no rendimento escolar do aluno. Para aprofundar essa relação entre escola e sociedade é fundamental buscarmos apoio em Pierre Bourdieu. Para Ione Valle (2007) a obra de Bourdieu torna-se, fundamental para o desenvolvimento de uma 'sociologia da educação crítica', capaz de romper com o ciclo do 'otimismo pedagógico', ainda predominante no sistema educacional, sobretudo nos discursos oficiais.

\begin{abstract}
Todo o sistema escolar está construído para identificar e reificar a inteligência, valorizar o dom e a vocação: inteligentes, dotados e vocacionados têm acesso à ciência e à cultura e serão bem-sucedidos na escola e fora dela; os demais devem acomodar-se nas habilitações sem prestígio, ocupar as funções inferiores e contentar-se com as posições subalternas (adequadas para os que não conseguiram chegar aos níveis mais elevados da pirâmide escolar). (VALLE, 2007, p.10)
\end{abstract}

Para a autora, Bourdieu procura demonstrar como se dá a adesão dos agentes sociais à ordem estabelecida e como o sistema de ensino está implicado nessa adesão, nessa cumplicidade impensada, pré-reflexiva, incorporada pelas formas de seleção e classificação, sancionadas e reproduzidas pela escola. Uma abordagem de Bourdieu sobre a teoria dos capitais também nos ajuda a elucidar a influência desta realidade extra-classe do aluno no seu rendimento escolar.

Para Barbosa (2007) quando analisamos a relação da escola com as famílias de classes populares, há uma relação de superioridade da instituição escolar com relação à realidade das famílias. Para a autora, o polo dominante é a escola, e respectivamente os professores, pois são eles que controlam os tempos e os espaços das aprendizagens, ensinam temas abstratos por meio de atividades descontextualizadas e realizam uma ação educativa fundamentalmente moralizadora. Segundo a autora, mesmo com as mudanças pedagógicas implementadas nos últimos anos, as escolas conservam esta lógica específica de socialização e defendem apenas um modo de ser, de pensar, de responder, isto é, apenas uma forma de cultura que é reconhecida como "a legítima".

Percebe-se assim que as famílias de camadas populares terão uma relação mais assimétrica em relação à escola do que as famílias de classe média alta. Para pensar essa relação de desigualdade entre realidade familiar e contexto escolar, o sociólogo da educação Bernstein (1996) criou o conceito de código. Segundo o autor, em função da 
classe social, existem diferenças nos códigos de comunicação dos filhos da classe trabalhadora e dos filhos da classe média. Estas diferenças, de acordo com o autor irão refletir nas relações de classe e de poder na divisão social do trabalho, família e escolas. Por exemplo, uma criança filha de pais analfabetos que exercem uma atividade laboral braçal e que não possuem uma linguagem nem sequer próxima da linguagem dos professores, se sentirão ainda mais distantes da escola bem como do conhecimento científico. Aqui também podemos recorrer à teoria de Bernstein sobre o discurso pedagógico e a recontextualização deste discurso na sociedade e nos grupos familiares. Para Mainardes \& Stremel (2010, p.15) a família e a comunidade podem "influenciar o campo recontextualizador da escola e interferir em sua prática, assim como a escola pode incorporar os discursos da família/comunidade e validar o seu discurso regulador".

Para compreendermos o processo de aprendizagem e assimilação dos conteúdos escolares se faz necessário o entendimento do contexto social, geográfico e familiar do aluno, por meio do qual este saber escolar é aprendido. E neste processo interrelacional também se compreende a forma como se exerce o controle social e a regulação de comportamentos e atitudes por parte das instituições, sejam elas a família ou a escola.

As reflexões quanto à relação entre educação, e contexto social/familiar do aluno servirão de fundamentação para identificarmos o papel determinante das condições socioeconômicas e culturais no rendimento escolar dos alunos.

\section{A realidade socioeconômica e o rendimento escolar: uma análise comparativa entre a fronteira e região central do estado do rio grande do sul}

Abordaremos a relação entre a realidade socioeconômica e o rendimento escolar dos alunos, a partir de uma comparação entre dois grupos de municípios, - como já citado anteriormente. $\mathrm{O}$ primeiro grupo é composto por municípios localizados na região fronteiriça do Estado do Rio Grande do Sul, pertencentes à $35^{\mathrm{a}}$ e $10^{\mathrm{a}} \mathrm{CRE}$ (Coordenadoria Regional de Educação) e o segundo grupo, composto por municípios localizados na região central e serrana do Estado mais próximos à capital, pertencentes à $4^{\text {a }}$ CRE. Apresentaremos inicialmente a tabela com os indicadores de cada município e posteriormente uma análise dos dados:

Tabela 1 - Indicadores socioeconômicos e educacionais dos municípios da fronteira oeste e região central/serrana do Estado do Rio Grande do Sul $^{2}$

\begin{tabular}{|c|c|c|c|c|c|c|c|}
\hline $\begin{array}{l}\text { CRE - } \\
\text { Coordenadori } \\
\text { a Regional de } \\
\text { Educação }\end{array}$ & Município & $\begin{array}{l}\text { População } \\
\text { (Censo } \\
\text { 2010) }\end{array}$ & $\begin{array}{l}\text { Crescimento } \\
\text { anual da } \\
\text { população } \\
\mathbf{2 0 0 0}-\mathbf{2 0 1 0} \\
(\%)\end{array}$ & $\begin{array}{l}\text { IDEB } \\
2011^{3}\end{array}$ & $\begin{array}{l}\text { IDH } \\
(2010)\end{array}$ & $\begin{array}{l}\text { Percentua } \\
\text { l de } \\
\text { pobreza } \\
(2010)\end{array}$ & $\begin{array}{l}\text { Percentual } \\
\text { da renda } \\
\text { apropriad } \\
\text { a pelos } \\
20 \% \text { mais } \\
\text { ricos } \\
(2000)\end{array}$ \\
\hline \multirow[t]{2}{*}{$35^{\mathrm{a}}$ (Fronteira) } & $\begin{array}{l}\text { Capão do } \\
\text { Cipó }\end{array}$ & 3.107 & 0,00 & 3,6 & 0,672 & 21,85 & $\begin{array}{l}\text { Não } \\
\text { disponível }\end{array}$ \\
\hline & Itacorubi & 3.441 & $-0,18$ & 2,9 & 0,657 & 20.08 & 58.0 \\
\hline
\end{tabular}

2 Os indicadores foram extraídos do Atlas do Desenvolvimento Humano (PNUD, 2013) que sistematizou os índices do Instituto Brasileiro de Geografia e Estatística e do Ministério da Educação.

3 Índice de Desenvolvimento da Educação Básica (IDEB) referente ao $9^{\circ}$ ano das escolas públicas dos referidos municípios em análise 


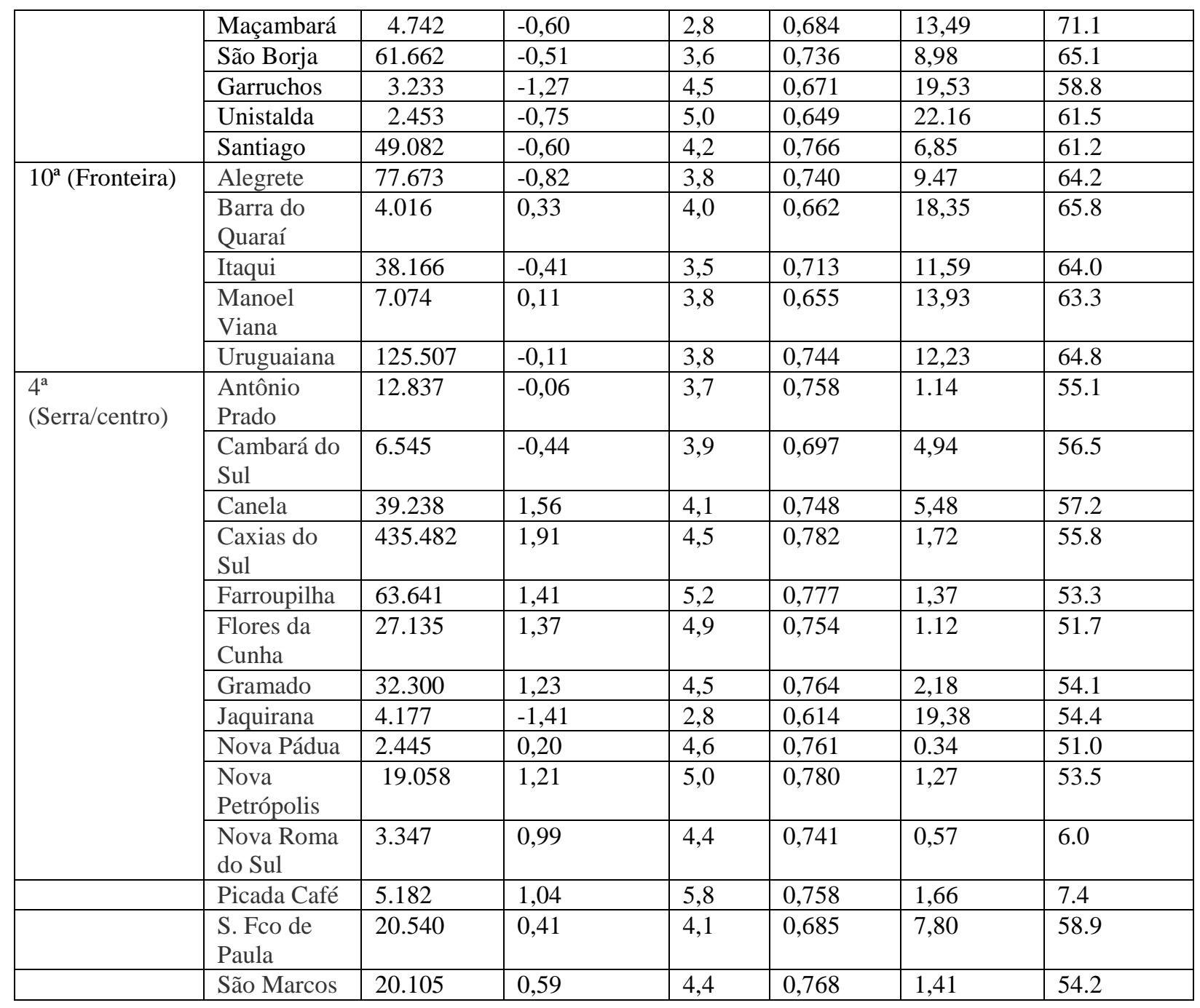

Fonte: o Autor

Numa primeira análise dos indicadores educacionais, é possível perceber que há uma clara relação entre a educação e os indicadores socioeconômicos. Dentre os dez municípios com os piores IDEBs (entre 2,8 e 3,8) oito estão localizados na região de fronteira e cinco deles estão entre os piores IDHs. Dentre os dez municípios com os melhores IDEBs oito estão localizados na região central e serrana. Na mesma perspectiva, dos dez municípios com os melhores IDEBs, sete deles possuem os melhores IDHs. Dentre os dez municípios com maior percentual de pobreza estão os sete municípios com os piores IDEBs. Dentre os doze municípios com os melhores IDEBs, nove deles possuem os menores percentuais de pobreza.

Todas essas análises nos levam a concluir que melhores níveis de distribuição de renda e menores índices de pobreza correspondem a melhores índices educacionais, e os baixos índices educacionais correspondem a baixos índices socioeconômicos e de qualidade de vida.

Numa analise comparativa entre as regiões (fronteira e serra/centro) são possíveis vários apontamentos, o primeiro deles refere-se aos IDEBs, onde a média dos municípios da fronteira alcança o índice de 3,79, já na região central e serrana esta media sobe para 4,42. Com relação ao crescimento anual da população, dos doze municípios da fronteira, 
dez deles apresentam um decrescimento populacional. Por outro lado, dentre os quatorze municípios da região serrana/central, apenas três apontam um decrescimento. Com relação ao IDH, a média da região de fronteira é menor do que a região serrana/central. Com relação ao percentual de pobreza, dos dez municípios que ultrapassaram o índice de $10 \%$ de pobres, nove deles estão na região de fronteira.

\section{CONSIDERAÇÕES FINAIS}

Esta breve análise nos faz concluir que a melhoria dos índices educacionais, e consequentemente do rendimento escolar dos alunos depende de uma melhor distribuição de renda, diminuição da pobreza e melhoria do desenvolvimento humano como um todo. Numa mesma perspectiva a análise demonstra uma situação mais desfavorável da região da fronteira em relação à região serrana e central do estado. Com uma desigualdade de renda elevada, maiores índices de pobreza bem como piores IDHs, a região da fronteira também detém os piores indicadores educacionais.

Retomando a relação entre educação e realidade socioeconômica, Bernstein(1996), considera que a classe social vai determinar uma aproximação ou distanciamento do aluno e da sua família para com a escola. E estas diferenças de acordo com o autor refletirão nas relações de classe e de poder na divisão social do trabalho, família e escolas. E aqui retomamos a questão da recontextualização do discurso pedagógico nos grupos familiares. Mainardes e Stremel (2010) ao discutirem esse conceito de Bernstein, consideram que todo discurso e práticas escolares estão sujeitos a princípios recontextualizadores provindos do contexto cultural primário do aluno. Assim, a realidade social, econômica e cultural da família e da comunidade pode influenciar na compreensão ou não do discurso produzido pela escola, seja no campo dos saberes científicos, seja mesmo no universo cultural. E aqui entra novamente tanto o contexto da região da fronteira, marcado por baixos indicadores sociais, o que vai colocar as famílias numa situação assimétrica para com a escola, onde tanto professores, quanto gestores possuem um nível sócioeconômico, e cultural bem acima da maioria das famílias.

Portanto ao defendermos o discurso de uma educação de qualidade ou mesmo do papel importante da educação como catalizadora de mudanças sociais, Dourado (2007) reforça que o desafio está em conferir ao termo qualidade educacional, uma conotação sócio histórica, não reduzida apenas à questão do rendimento escolar. Nesse sentido, para o autor, pensar a qualidade social da educação implica assegurar um processo pedagógico pautado pela eficiência, eficácia e efetividade social, de modo a contribuir com a melhoria da aprendizagem dos educandos, em articulação com a melhoria das condições de vida e de formação da população. Logo, a melhoria da qualidade da educação brasileira estará envolta em princípios, que são tanto técnicos quanto políticos, e na produção e implementação de ações que promovam condições de melhoria educacional. O Plano Nacional de Educação - PNE (BRASIL, 2001) propõe em dois de seus objetivos a melhoria da qualidade de ensino em todos os níveis e a redução das desigualdades sociais e regionais no tocante ao acesso e permanência com sucesso, na educação pública.

Percebe-se, portanto que a questão da qualidade educacional está imersa em um contexto de múltiplos fatores determinantes. Por outro lado, o Estado precisa, por meio de alguns indicadores, mensurar a qualidade de ensino para elaborar suas políticas públicas. Para Passador \& Alves (2011), a educação não foge à tendência da administração pública 
contemporânea que considera fundamental o acompanhamento de todas as políticas públicas através de critérios de avaliação, por acreditar que o desconhecimento dos efeitos de um programa ou projeto público pode ser muito grave. Na educação básica, o indicador que, hoje, sintetiza e avalia o desenvolvimento educacional é o IDEB (Índice de Desenvolvimento da Educação Básica).

Um estudo realizado por Freitas e outros (2011) acerca da avaliação em larga escala, aponta que ainda é o nível socioeconômico que determina o rendimento escolar. De acordo com os autores, numa pesquisa em 34 escolas da rede pública brasileira observouse que à medida que o nível socioeconômico diminui, aumenta o nível de reprovação, contrariando assim o objetivo das políticas. Diante disso, pergunta-se: O Ideb está promovendo nas escolas um processo de amenização das diferenças de rendimento escolar principalmente entre os mais desprovidos de capital econômico e cultural? Sousa (2003) alerta para o fato de que a avaliação em larga escala das redes públicas de educação possui um potencial de condicionar os currículos e, desse modo, intensificar desigualdades escolares e sociais.

\section{REFERÊNCIAS}

BARBOSA, M C S. Culturas escolares, culturas de infância e culturas familiares: as socializações e a escolarização no entretecer destas culturas. Educ. Soc., Campinas, v. 28, n. 100, out. 2007. Disponível em: < http://www.scielo.br/pdf/es/v28n100/a2028100.pdf>. Acesso em: 25 set. 2010

BERNSTEIN, B. A estruturação do discurso pedagógico: classe, códigos e controle. Vozes: Petrópolis, 1996.

BRASIL, Lei n. 10.172, de 9/01/2001. Aprova o Plano Nacional de Educação. Disponível em: www.senado.org.br. Acesso em: 28 jan. 2016

DOURADO, L F. Políticas e gestão da educação básica no Brasil: limites e perspectivas. Educação \& Sociedade, Campinas, vol. 28, n.100 - Especial, p. 921-946, out. 2007. P.940

FREITAS, L C; SORDI, M R; MALAVASI, M; FREITAS, H. Avaliação Educacional: caminhando pela contramão. Petrópolis: Vozes. 2011

FRIGOTTO, G; CIAVATTA, M. Educação básica no Brasil na década de 1990: subordinação ativa e consentida à lógica do mercado. Educ. Soc. , Campinas, v. 24, n. 82, 2003 . Disponível em: http://www.scielo.br/scielo.php? =S010173302003000100005\&lng=pt\&nrm=iso>. Acesso em: 23 Jul 2016.

INSTITUTO BRASILEIRO DE GEOGRAFIA E ESTATÍSTICA (IBGE). Disponível em: <http://www.ibge.gov.br/cidadesat/topwindow.htm?1.> Acesso em: 30 mar. 2016 
MAINARDES, J; STREMEL, S. A teoria de Basil Bernstein e algumas de suas contribuições para as pesquisas sobre políticas educacionais e curriculares. Revista Teias $\mathrm{v}$. 11 • n. 22 • xxx-yyy •maio/ago. 2010. Disponível em: $<\mathrm{http}: / / \mathrm{www}$.periodicos.proped.pro.br/index.php?journal=revistateias\&page=article\&op=v iew\&path\%5B\%5D=575> Acesso em 13 set. 2016. p.15

MINISTÉRIO DA EDUCAÇÃO - MEC. Instituto Nacional de Estudos e Pesquisas Educacionais Anísio Teixeira - INEP. Censo 2002. Brasília-DF. 2002

MÉSZÁROS, I. A Educação para além do capital. São Paulo: Boitempo. 2005

PASSADOR, C; ALVES, T. Educação Pública no Brasil: condições de oferta, nível socioeconômico dos alunos e avaliação. São Paulo: Annablume; Brasília: Capes e Inep. 2011.

SOUSA, S Z L. Possíveis impactos das políticas de avaliação no currículo escolar. Cadernos de Pesquisa, São Paulo, n. 119, p. 175-190, jul. 2003.

VALLE, I R. A obra do sociólogo Pierre Bourdieu: uma irradiação incontestável. Revista Educação e Pesquisa, São Paulo, v.33, n.1, p. 117-134, jan./abr. 2007.

Recebido em: 05/02/2017

Aprovado em: 02/03/2017 